\title{
To See or NOsee: The Debate on the Nocebo Effect and Optimizing the Use of Biosimilars
}

Mourad F. Rezk · Burkhard Pieper

Received: April 16, 2018 / Published online: June 5, 2018

(C) The Authors 2018, corrected publication August/2018 clinical trials, and that this effect may negatively affect acceptance in patients switching from an originator product to a biosimilar. Awareness of the potential for the nocebo effect and adoption of enhanced communication techniques may be useful in mitigating the nocebo effect. Effective healthcare professional-patient dialogue is key in transferring confidence to the patient, and has been shown to reduce nocebo effects in patients when switching from an originator to a biosimilar.

Funding: Biogen International $\mathrm{GmbH}$.

Keywords: Biosimilar; Education; Nocebo effect; Physician-patient dialogue

\section{COMMENTARY}

The nocebo effect is a little-known phenomenon that can cause the induction or the worsening of symptoms by sham or active therapies $[1,2]$. It is the opposite of the positive, placebo effect and may account for some adverse events (AEs) reported by patients following treatment. Nocebo responses may occur as an unintentional effect of the requirement for healthcare professionals to explain possible complications and side effects when initiating treatment, particularly if this is done with only minimal explanation and discussion with the patient $[1,3]$. A nocebo effect may also occur as a result of non-verbal behavior. If the healthcare 
professional holds negative beliefs or concerns, or lacks confidence in a treatment, this may be translated in body language and tone of voice when discussing different options [1, 3]. Based on the information provided by the healthcare professional, or indeed based on news and online media reports, patients develop expectations of treatment effectiveness and side effects, which in turn may influence the number and type of symptoms that they report following treatment initiation [3]. This may be true for biosimilars, in the same way as for generic drugs [4]. Although healthcare providers are becoming increasingly familiar with prescribing biosimilars, some may not be fully aware of the rigorous regulatory basis for biosimilar approval, which may lead to uncertainty about the use of biosimilars in their daily clinical practice. While perceptions of efficacy and safety for biosimilars may be lower than for the original product, patients who are familiar with biosimilars tend to have more positive views than patients who never received them [4].

At the 2017 American College of Rheumatology/Association of Rheumatology Health Professionals annual meeting, a debate took place on the benefits and consequences of switching patients to biosimilar agents [5]. One topic that was discussed by Professor Fleischmann and Professor Kay was the validity of the nocebo effect. The question was asked as to whether the nocebo effect was in fact being used to describe "any result you don't agree with", a provocative query to spark debate in the session, which disregards evidence accumulated in at least 10 different disease areas $[2,6]$. To add to this discussion and to build upon previous work, including our recent publication on the same topic [4], we will review here how the nocebo effect may affect patients receiving biosimilars, as well as strategies to mitigate these.

To receive regulatory approval for a biosimilar, a step-wise process is followed. This begins with establishing similarity in terms of critical quality attributes and biological activity of the biosimilar candidate and its reference product, followed by clinical studies demonstrating similarity in terms of pharmacokinetics and pharmacodynamics (the latter if feasible) [7]. Finally, randomized, clinical studies are performed, to demonstrate equivalent efficacy and comparable safety and immunogenicity between the biosimilar and the reference product. Based on the totality of evidence presented and by providing approval of the biosimilar, regulatory authorities acknowledge that there are no clinically meaningful differences between the biosimilar and its reference product.

To date, multiple well-designed clinical trials have confirmed that biosimilars are equivalent in terms of efficacy and have comparable safety profiles with the original reference product [8-14]. Furthermore, a randomized, extension study in which patients receiving originator infliximab were re-randomized to continue treatment or to switch to the biosimilar SB2, and patients previously receiving SB2 continued unchanged, reported that the efficacy, safety, and immunogenicity profiles continued to be comparable among the three treatment groups up to the end of the study (week 78) [15]. Additionally, NOR-SWITCH, a Norwegian government-sponsored randomized, non-inferiority, double-blind, Phase IV trial, was designed to generate additional evidence on switching to a biosimilar. This showed that switching from infliximab originator to CT-P13 was not inferior to the infliximab originator, using a prespecified non-inferiority margin of $15 \%$ in terms of disease worsening according to disease-specific composite measures [14]. Real-world data also generally support the conclusion that there are no clinically meaningful objective differences in effectiveness or safety profile between biosimilars and originator products, but subjective, nocebo effects have been reported. A recently reported pragmatic 1-year study assessed the incidence of a nocebo effect when switching from originator infliximab to a biosimilar in patients with inflammatory bowel or rheumatic diseases [16]. After a detailed informed consent process explaining the nonmedical switch, no difference was reported in either objective effectiveness or safety variables up to 9 months post-switch, whereas a nocebo response (defined as an unexplained, unfavorable therapeutic effect subsequent to a non- 
medical switch from originator infliximab to biosimilar infliximab with regaining of the beneficial effects after reinitiating the originator) of $12.8 \%$ was reported at 6 months postswitch. Another observational, single clinic study performed in Norway included 39 patients with rheumatoid arthritis or ankylosing spondylitis who were switched from originator infliximab to a biosimilar. A nocebo effect (discontinuation of treatment due to subjective reasons with no objective deterioration of disease) of $15 \%$ after a median of 11 months was reported [16, 17]. Additional evidence taken from registry studies, as well as single-center experiences, has shown a possible trend for patients to discontinue biosimilar treatment, mainly due to reported lack of effectiveness or AEs [18-24]. Although these data differences may cause concern, retention rates have been found to be generally comparable with those seen with historic originator data or rates seen during the control period prior to biosimilar switch [20, 24].

Given the rigorous, scientific review of biosimilars compared with the reference product, these reported differences are unlikely to result from the biosimilars' benefit-risk profile, leading some authors to suggest that this is probably due to the nocebo effect. Data from the BIO-SWITCH study demonstrated that switching to a biosimilar led to differences in subjective assessments (e.g., patient global disease activity, patient-reported tender joint count), but not objective measurements (e.g., physician-reported swollen joint count, C-reactive protein levels) [25]. A nocebo effect could also be suspected in the PRESERVE trial in patients receiving two different etanercept doses or placebo. When patients' treatment dose was halved during a double-blind period, a continuation of good responses was also maintained in the group receiving the reduced dose [26].

Knowing that nocebo effects may occur when switching to biosimilars, healthcare professionals should be aware of informed shared decision-making strategies that can be employed to mitigate these effects. A recent real-world study employed an enhanced communication strategy for switching to biosimilar etanercept. This included informing patients that lower costs and fewer injection site reactions were the reason for transitioning, and providing 'soft skills' training for rheumatology and pharmacy staff regarding the management of patient concerns towards biosimilars, including how to respond to patients reporting health complaints (e.g., discuss possible nocebo effects and incorrect causal attribution). The enhanced communication strategy was associated with higher persistence rates compared with those for patients who were not exposed to this approach [23]. This demonstrates that patient education and support as part of the informed decision-making process prior to initiating a switch to a biosimilar can improve patient acceptance and reduce potential nocebo effects [23]. Furthermore, recent guidance and information provided by the EMA supports this strategy; they state that "any decision on switching should involve the prescriber in consultation with the patient, and take into account any policies that the country might have regarding the prescribing and use of biological medicines". [7, 27].

\section{CONCLUSIONS}

The nocebo effect may negatively affect acceptance in patients switching to a biosimilar. Awareness of the potential for the nocebo effect when switching patients from an originator product to a biosimilar and adoption of enhanced communication techniques may be useful in mitigating the nocebo effect. Effective healthcare professional-patient dialogue is key to transferring confidence to the patient, and has been shown to reduce nocebo effects in patients when switching from an originator to a biosimilar.

\section{ACKNOWLEDGEMENTS}

Funding. Article processing charges were funded by Biogen International $\mathrm{GmbH}$. Biogen reviewed for scientific accuracy and provided feedback to the authors. The authors had full 
editorial control of the paper, and provided their final approval of all content.

Medical Writing and/or Editorial Assistance. Biogen International $\mathrm{GmbH}$ provided funding for medical writing support in the development of this paper; Rugina Ali and Catherine Lee from Syneos Health, London, UK, wrote the first draft of the manuscript based on input from authors, and Robert Harries from Syneos Health, London, UK, copyedited and styled the manuscript per journal requirements.

Authorship. All named authors meet the International Committee of Medical Journal Editors (ICMJE) criteria for authorship for this manuscript, take responsibility for the integrity of the work as a whole, and have given final approval to the version to be published.

Disclosures. Mourad Farouk Rezk is an employee of Biogen International $\mathrm{GmbH}$ and therefore receives a salary and may own Biogen stock. Burkhard Pieper is an employee of Biogen International $\mathrm{GmbH}$ and therefore receives a salary and may own Biogen stock.

Compliance with Ethics Guidelines. This article is based on previously conducted studies, and does not involve any new studies of human or animal subjects performed by any of the authors.

Open Access. This article is distributed under the terms of the Creative Commons Attribution-NonCommercial 4.0 International License (http://creativecommons.org/licenses/ by-nc/4.0/), which permits any noncommercial use, distribution, and reproduction in any medium, provided you give appropriate credit to the original author(s) and the source, provide a link to the Creative Commons license, and indicate if changes were made.

\section{REFERENCES}

1. Hauser W, Hansen E, Enck P. Nocebo phenomena in medicine: their relevance in everyday clinical practice. Dtsch Arztebl Int. 2012;109:459-65.
2. Planes S, Villier C, Mallaret M. The nocebo effect of drugs. Pharmacol Res Perspect. 2016;4:e00208.

3. Faase K, Petrie K. The nocebo effect: patient expectations and medication side effects. Postgrad Med J. 2013;89:540-6.

4. Rezk MF, Pieper B. Treatment outcomes with biosimilars: be aware of the nocebo effect. Rheumatol Ther. 2017;4:209-18.

5. Fleischmann R, Kay J. Great Debate: biosimilars. To switch or not to switch? https://www. rheumatology.org/About-Us/Newsroom/Press-Rele ases/ID/824/Biosimilars-Take-Center-Stage-at-2017ACRARHP-Annual-Meeting. Accessed 16 Feb 2018.

6. Gupta A, Thompson D, Whitehouse A, et al. Adverse events associated with unblinded, but not with blinded, statin therapy in the Anglo-Scandinavian Cardiac Outcomes Trial-Lipid-Lowering Arm (ASCOT-LLA): a randomised double-blind placebocontrolled trial and its non-randomised non-blind extension phase. Lancet. 2017;389:2473-81.

7. EMA. Biosimilars in the EU. 2017. http://www.ema. europa.eu/docs/en_GB/document_library/Leaflet/ 2017/05/WC500226648.pdf. Accessed 13 Mar 2018.

8. Yoo DH, Hrycaj P, Miranda P, et al. A randomised, double-blind, parallel-group study to demonstrate equivalence in efficacy and safety of CT-P13 compared with innovator infliximab when coadministered with methotrexate in patients with active rheumatoid arthritis: the PLANETRA study. Ann Rheum Dis. 2013;72:1613-20.

9. Yoo DH, Racewicz A, Brzezicki J, et al. A phase III randomized study to evaluate the efficacy and safety of CT-P13 compared with reference infliximab in patients with active rheumatoid arthritis: 54-week results from the PLANETRA study. Arthritis Res Ther. 2016;18:82.

10. Emery P, Vencovsky J, Sylwestrzak A, et al. A phase III randomised, double-blind, parallel-group study comparing SB4 with etanercept reference product in patients with active rheumatoid arthritis despite methotrexate therapy. Ann Rheum Dis. 2017;76:51-7.

11. Park W, Yoo DH, Miranda P, et al. Efficacy and safety of switching from reference infliximab to CTP13 compared with maintenance of CT-P13 in ankylosing spondylitis: 102-week data from the PLANETAS extension study. Ann Rheum Dis. 2017;76:346-54.

12. Yoo DH, Prodanovic N, Jaworski J, et al. Efficacy and safety of CT-P13 (biosimilar infliximab) in patients with rheumatoid arthritis: comparison between switching from reference infliximab to CT- 
P13 and continuing CT-P13 in the PLANETRA extension study. Ann Rheum Dis. 2017;76:355-63.

13. Griffiths CEM, Thaci D, Gerdes S, et al. The EGALITY study: a confirmatory, randomized, doubleblind study comparing the efficacy, safety and immunogenicity of GP2015, a proposed etanercept biosimilar, vs. the originator product in patients with moderate-to-severe chronic plaque-type psoriasis. Br J Dermatol. 2017;176:928-38.

14. Jorgensen KK, Olsen IC, Goll GL, et al. Switching from originator infliximab to biosimilar CT-P13 compared with maintained treatment with originator infliximab (NOR-SWITCH): a 52-week, randomised, double-blind, non-inferiority trial. Lancet. 2017;389:2304-16.

15. Smolen JS, Choe J-Y, Prodanovic N, et al. Safety, immunogenicity and efficacy after switching from reference infliximab to biosimilar SB2 compared with continuing reference infliximab and SB2 in patients with rheumatoid arthritis: results of a randomised, double-blind, phase III transition study. Ann Rhuem Dis. 2018;77:234-40.

16. Boone NW, Liu L, Romberg-Camps MJ, et al. The nocebo effect challenges the non-medical infliximab switch in practice. Eur J Clin Pharmacol. 2018;74:655-61.

17. Nikiphorou E, Kautiainen $\mathrm{H}$, Hannonen $\mathrm{P}$, et al. Clinical effectiveness of CT-P13 (Infliximab biosimilar) used as a switch from Remicade (infliximab) in patients with established rheumatic disease. Report of clinical experience based on prospective observational data. Expert Opin Biol Ther. 2015;15:1677-83.

18. Edwards C. Switching patients from originator to biosimilar medications in rheumatoid arthritis: limiting the 'nocebo' effect. EMJ Rheumatol. 2017;4:42-8.

19. Glintborg B, Omerovic E, Danebod K et al. One-year clinical outcomes in 1623 patients with inflammatory arthritis who switched from originator to biosimilar etanercept-an observational study from the danish danbio registry. Arthritis Rheumatol. 2017;69(suppl 10):Abstract 1550.
20. Holroyd C, Wallis D, Bennett S, et al. AB0377 switching from bio-original etanercept to biosimilar etanercept SB4: patient acceptability and outcomes in the real world. Ann Rheum Dis. 2017;76(Suppl 2):1180.

21. Rabbitts R, Jewell T, Marrow K-L, et al. Switching to biosimilars: an early clinical review. Rheumatology. 2017;56(Suppl 2):132.

22. Sigurdartorri V, Husmark T, Svard A. Switching from reference product etanercept to the biosimilar SB4 in a real-life setting: follow-up of 147 patients. Ann Rheum Dis. 2017;76(Suppl 2):835.

23. Tweehuysen L, Huiskes V, Bemt BVD, et al. FR10200 higher acceptance and persistence rates after biosimilar transitioning in patients with a rheumatic disease after employing an enhanced communication strategy. Ann Rheum Dis. 2017;76(Suppl 2):557.

24. Glintborg B, Sorensen IJ, Loft AG, et al. A nationwide non-medical switch from originator infliximab to biosimilar CT-P13 in 802 patients with inflammatory arthritis: 1-year clinical outcomes from the DANBIO registry. Ann Rheum Dis. 2017;76:1426-31.

25. Tweehuysen L, van den Bemt BJF, van Ingen IL, et al. Subjective complaints as the main reason for biosimilar discontinuation after open-label transition from reference infliximab to biosimilar infliximab. Arthritis Rheumatol. 2018;70:60-8.

26. Smolen JS, Nash P, Durez P, et al. Maintenance, reduction, or withdrawal of etanercept after treatment with etanercept and methotrexate in patients with moderate rheumatoid arthritis (PRESERVE): a randomised controlled trial. Lancet. 2013;381:918-29.

27. What I need to know about biosimilar medicines. Information for patients. https://ec.europa.eu/ docsroom/documents/26643/attachments/1/translat ions/en/renditions/native. Accessed May 2018. 